\title{
EFFICACY OF USING INTRAVAGINAL MISOPROSTL IN MID-TRIMESTER MISSED ABORTION
}

\author{
Naher $S^{1}$, Begum $K^{2}$, Hakim $M^{3}$
}

\begin{abstract}
Introduction: Termination of missed abortion in the second trimester by suction evacuation is more traumatic than in early pregnancy. Misoprostl is effective in first and second trimester abortions. Vaginal route being superior to oral.
\end{abstract}

Objectives: The study was carried out to evaluate the effectiveness and safety of vaginal Misoprostl in the management of second trimester missed abortion.

Methods: This prospective study was carried out in the department of Obstretrics and Gynaecology, Dhaka Medical College Hospital from January 2004 to December 2004. A total 50 missed abortion patients were randomly selected. After required investigations Tab Misoprostol 200 ug was introduced per vagina in the posterior fornix which was repeated every four hours. The incidence of complete expulsion and side effect was examined. The patient who did not respond to Misoprostol, Oxytocin infusion was given to them after 6 hours of the last doses of Misoprostol. If the patient failed to respond, surgical evacuation was attempted. Ultrasonogram was done after 12 hours to confirm complete abortion.

Results: Among the 50 cases 38 (76\%) had gestation age within the range of 13-24 weeks. Twenty five (50\%) cases required only Misoprostol for expulsion of product of conception with range of 1-4 doses. Eight (16\%) required misoprostol with oxytocin drip \& 17 (34\%) required surgery even after misoprostol \& oxytocin. The induction-expulsion interval of $25(50 \%)$ cases was $11 \pm 4$ in 25 women who were given Tab Misoprostol only. Forty three (86\%) had no side effects \& well-tolerated with the drug. Only Misoprostol is required in gestational age group of 21-24 weeks $(64.3 \%)$ \& $25-28$ weak (66.7\%). Misoprostol was successfully used in most Nulliparous women $(64.7 \%)$ \& Primiparous women $(42.9 \%)$.

Conclusion: The second trimester missed abortion termination by srgical evacuation is traumatic and complications are more. If Tab Misoprostol proves safe and effective a large number of patients will be benefited and will escape from surgical intervention and complications.

Key-words: Missed abortion, Prostaglandin, Trimester.

\begin{abstract}
Introduction
Missed abortions would probably expel spontaneously in the long-term, but there may be a delay of weeks or months and many women become distressed once the diagnosis is made ${ }^{1}$. Therefore, active management is often chosen. When decision for termination of pregnancy is taken the safe and effective method has long been a challenge ${ }^{2}$. During the second trimester, the uterus is quiescent and non-responsive. At this stage, termination by suction evacuation is more traumatic than that in early pregnancy and complication is common and may be severe ${ }^{3}$. Surgical evacuation is the most common method of treatment of missed abortion. It is considered to be safe but carries a risk of complications related to anesthesia and surgical complications such as uterine perforation, cervical-trauma, intrauterine adhesions and infection ${ }^{4}$. Medical treatment of missed abortion with vaginal Misoprostol induces more complete evacuation as compare to expectant management ${ }^{5}$. Medical management is safe and cheaper than surgical evacuation.
\end{abstract}

1. Dr. Salma Naher, MBBS, MS, FCPS, Junior Consultant, Kurmitola General Hospital, Dhaka; 2. Prof Kohinoor Begum (Rtd), MBBS, FCPS, Ex Head, Dept of Gynaecology \& Obstetrics, Dhaka Medical College, Dhaka; 3. Lt Col Maksumul Hakim, MBBS, MPH, Mphill, BANBAT-24. 
Prostaglandins and their synthetic analogues are successfully employed in the termination of second trimester pregnancy losses using different routes of administration ${ }^{6}$. There is continual search for better agents, routes of administration and doses of prostaglandins for medical termination of pregnancy. At the present time, misoprostol in combination with anti-progesterone seems to be the best ${ }^{7}$. Misoprostol is a Prostaglandin E-1 analog that has a lower cost and stable at room temperature and fewer side effects than E-2 anglogues ${ }^{8}$. Misoprostol can be used orally or vaginally. The bioavailability of Misoprostol is three times higher when used vaginally that of orally and oral use is associated gastrointestinal side effects ${ }^{9}$. Misoprostol has been used widely in Obstetric and Gynaecologic practices because of its effectiveness, low cost, rapid absorption, stability at room temperature and ease of administration. A large number of studies have shown that Misoprostol is effective in first and second trimester abortions. Vaginal route being superior to oral. The most frequent side effects include nausea, vomiting, diarrhoea and low grade fever. Dose dependent uterine hyper-contractility /hyper-stimulation are an additional concern ${ }^{10}$. Aim of the present study is to evaluate the effectiveness and safety of vaginal Misoprostol in the management of second trimester missed abortion.

\section{Materials and Methods}

This prospective observational study was conducted in Dhaka Medical college Hospital between the periods from January 2004 to December 2004. During the study period, a total of 50 randomly selected women with ultrasonographically diagnosed cases of mid-trimester missed abortion who were admitted in the department of Obstetrics \& Gynaecology were included in this study. Women with bronchial asthma \& known hypersensitivity to prostaglandins were excluded. After obtaining informed consent, taking detailed history and performing necessary examination, an ultra- sonogram was taken as an integral part of diagnosing cases of missed abortion. Tab Misoprostol (Cytomis,1tab=200 ug) was introduced per vagina and applied in the posterior fornix. The doses were repeated every 4 hours for a total of maximum four doses or until expulsion of the product of conception. Patients were followed up 4-hour interval or whenever they complained of any problem. Patient who did not respond (even after four doses of Misoprostol therapy), Oxytocin infusion was started 4 hours after the last dose of Misoprostol. In spite of Misoprostol and Oxytocin the patient who failed to respond, surgical evacuation was attempted. Ultrasonography was done after 12 hours to confirm complete abortion. The symptoms experienced during the use of Misoprostol were fever, nausea, vomiting, diarrhoea, \& need for blood transfusion were assessed and noted. All the collected raw data were organized into tabulated form. All the continuous data were expressed as mean \pm SD and categorical data in percentage (\%) and frequency (f).

\section{Results}

Table-I shows that most of the women belonged to age group 21-30 years (62\%). Mean ( \pm SD) age of the women was $26.32 \pm 6.06$ years (range 17-40 years).

Table-I: Age distribution of the patients $(n=50)$.

\begin{tabular}{|c|c|c|}
\hline Age (years) & No of Patients & Percentage \\
\hline$\leq 20$ & 10 & 20.0 \\
\hline $21-30$ & 31 & 62.0 \\
\hline$\geq 31$ & 9 & 18.0 \\
\hline
\end{tabular}

Table-ll shows that Mean $( \pm S D)$ gestation age of the women was $20.00 \pm 4.81$ weeks (range 13-28 weeks). Nineteen (38\%) cases belonged to $13-16$ weeks, $14(28 \%)$ belonged to 21-24 weeks, 12 (24\%) belonged to $25-28$ weeks and $5(10 \%)$ belonged to 17-20 weeks gestation age.

Table-II: Distribution of gestational age $(n=50)$.

\begin{tabular}{|c|c|c|}
\hline Gestation (weeks) & Number of patients & Percentage \\
\hline $13-16$ & 19 & 38.0 \\
\hline $17-20$ & 5 & 10.0 \\
\hline $21-24$ & 14 & 28.0 \\
\hline $25-28$ & 12 & 24.0 \\
\hline
\end{tabular}

In this study, 25 (50\%) women required only Tab Cytomis for expulsion of gestational sac and 8 $(16 \%)$ women required Oxytocin drip additionally. However the rest 17 (34\%) women required surgery when Tab Cytomis and Oxytocin drip failed to expel the gestational sac (Table-III). 
Table-III: Procedure required for expulsion of gestational sac $(n=50)$.

\begin{tabular}{|l|c|c|}
\hline \multicolumn{1}{|c|}{ Procedure } & $\begin{array}{c}\text { Number of } \\
\text { patients }\end{array}$ & Percentage \\
\hline Tab Cytomis & 25 & 50.0 \\
1 & & \\
2 & 3 & 12.0 \\
3 & 4 & 16.0 \\
4 & 10 & 40.0 \\
Tab Cytomis follwed by & 8 & 32.0 \\
Oxytocin drip & 8 & 16.0 \\
Tab Cytomis followed by \\
Oxytocin drip and then \\
surgery.
\end{tabular}

Only Tab Cytomis was required in maximum number of women in gestaional age group 21-24 weeks (64.3\%) and 25-28 weeks (66.7\%), Tab Cytomis and Oxytocin drip were used in maximum $4(28.6 \%)$ women in gestational age group 21-24 weeks, and surgery was required in maximum number of women in gestational age group 13-16 weeks $(57.9 \%)$ (Table-IV).

Table-IV: Relationship between gestational age and mode of induction $(n=50)$.

\begin{tabular}{|c|c|c|c|c|c|c|c|}
\hline $\begin{array}{c}\text { Gestation } \\
\text { (weeks) }\end{array}$ & N & \multicolumn{2}{|c|}{ Cytomis } & \multicolumn{2}{|c|}{$\begin{array}{c}\text { Cytomis } \\
\text { +Oxytocin }\end{array}$} & \multicolumn{2}{|c|}{$\begin{array}{c}\text { Cytomis } \\
\text { +oxytocin } \\
\text { + Surgery }\end{array}$} \\
\hline & & No & $(\%)$ & No & $(\%)$ & No & $(\%)$ \\
\hline $13-16$ & 19 & 6 & $(31.6)$ & 2 & $(10.5)$ & 11 & $(57.9)$ \\
\hline $17-20$ & 5 & 2 & $(40.0)$ & 1 & $(20.0)$ & 2 & $(40.0)$ \\
\hline $21-24$ & 14 & 9 & $(64.3)$ & 4 & $(28.6)$ & 1 & $(7.1)$ \\
\hline $25-28$ & 12 & 8 & $(66.7)$ & 1 & $(8.3)$ & 3 & $(25.0)$ \\
\hline
\end{tabular}

Mean $( \pm S D)$ time required for expulsion of product of conception was $11.44 \pm 4.43$ hours in 25 women who were given Tab Cytomis only, 20.13 \pm 1.25 hours in 8 women who were given Tab Cytomis followed by Oxytocin drip and $21.29 \pm 0.99$ hours in 17 women who required surgery when Tab Cytomis and Oxytocin drip failed to expel the product of conception (Table-V).
Table-V: Induction-expulsion interval in relation to mode of induction $(n=50)$.

\begin{tabular}{|c|c|c|c|}
\hline Induction & $\mathbf{n}$ & $\begin{array}{c}\text { Expulsion Time } \\
\text { Range (hr) }\end{array}$ & Mean \pm SD \\
\hline Tab Cytomis & 25 & $3.00-19.50$ & $11.44 \pm 4.43$ \\
\hline $\begin{array}{c}\text { Tab Cytomis } \\
\text { + Oxytocin drip }\end{array}$ & 8 & $19.00-22.00$ & $20.13 \pm 1.25$ \\
\hline $\begin{array}{c}\text { Tab Cytomis } \\
+ \text { Oxytocin drip } \\
\text { + Surgery }\end{array}$ & 17 & $20.00-22.00$ & $21.29 \pm 0.99$ \\
\hline
\end{tabular}

Vaginal Misoprostl treatment appeared to be well tolerated. Out of 7 patients with side-effects, only 1 patient showed significant gastrointesintinal side-effect, e.g. diarrhoea (Table-VI).

Table-VI: Side-effects $(n=50)$.

\begin{tabular}{|l|c|c|}
\hline Side-effects & Number of Patients & Percentage \\
\hline Nausea & 3 & 6.0 \\
\hline Fever & 2 & 4.0 \\
\hline Vomiting & 1 & 2.0 \\
\hline Diarrhoea & 1 & 2.0 \\
\hline No side-effect & 43 & 86.0 \\
\hline
\end{tabular}

Tab Cytomis was successfully used in most of Nulliparous women $(64.7 \%)$ and Primiparous women $(42.9 \%)$. Surgery was required mostly in Multiparous women $(52.6 \%)$ (Table-VII).

Table-VII: Relationship between parity and mode of induction $(\mathrm{n}=50)$.

\begin{tabular}{|c|c|c|c|c|}
\hline Parity & Number & $\begin{array}{c}\text { Cytomis } \\
\text { No }(\%)\end{array}$ & $\begin{array}{c}\text { Cytomis + Oxytocin } \\
\text { No no }(\%)\end{array}$ & $\begin{array}{c}\text { Cytomis+0xytocint } \\
\text { Surgery No (\%) }\end{array}$ \\
\hline Nulliparous & 17 & $11(64.7 \%)$ & $2(11.8 \%)$ & $4(23.5 \%)$ \\
\hline Primiparous & 14 & $6(42.9 \%)$ & $5(35.7 \%)$ & $3(21.4 \%)$ \\
\hline Multiparous & 19 & $8(42.1 \%)$ & $1(5.3 \%)$ & $10(52.6 \%)$ \\
\hline
\end{tabular}

\section{Discussion}

Missed abortion is a common complication of early pregnancy, occurring in up to 15 percent of all clinically recognized preganacies ${ }^{11}$. The majority of cases are currently treated by dilatation and curettage (D\&C). A small case series reported that seven of eight women with missed abortion had a complete abortion after treatment with vaginal Misoprostl compared with three of 12 treated by the oral route ${ }^{12}$. This study was carried out to find out the efficacy of this new drug (Misoprostl) in the expulsion of product of conception with special attention to number of doses required and induction- 
expulsion interval and need for additional Oxytocin/Surgical evacuation. In this study, 50 patients who fulfilled the inclusion criteria were enrolled. The demographic and clinical characteristics were evaluated. Mean $( \pm S D)$ age of the patients was $26.33 \pm 6.06$ years (range 17-40 years) and mean parity was mean \pm SD $1.32 \pm 1.28$ (range 0-4). Most of the patients were multiparous $(38 \%)$. Most of the patients came from average socioeconomic condition $(60 \%)$ and the mean $( \pm S D)$ gestational age was $20.00 \pm 4.81$ weeks (range 1328 weeks) Most of the study patients belonged to 13 -16 gestation (38\%).

In a study conducted by Zalanyi ${ }^{13}$ using vaginal misoprosstol for missed abortion, the characteristics of women showed mean ( $\pm S D$ ) age as $25.80 \pm 5.25$ years, gravidity $2.4 \pm 1.42$ and parity $1.0 \pm 0.84$. The study included only cases of amenorrhoea of up to 13 weeks, whereas, this study included mid-trimester cases. The efficacy of vaginal Misoprostl was also studied for medical management of missed abortion by Wood ${ }^{14}$, where gestational age of the patients ranged from 7 to 17 weeks (median 12 weeks). The mean $( \pm S D)$ age of the patients was $31.00 \pm 5.00$ and 56 percent of the patients were nulliparous. In both the above studies, vaginal Misoprostl was found to be quite effective in expulsion of production of conception in missed abortion cases, reducing the need for surgical evacuation. In this study, as in 50 percent (25 out of $50)$ experienced complete expulsion (12\% after Ist dose, $16 \%$ after 2 nd dose. $40 \%$ after 3 rd dose, and $32 \%$ after 4 th dose). Sixteen percent cases needed Oxytocin drip as an adjunct and 34 percent needed surgical evacuation when four dosed of Misoprostl (Tab Cytomis) and Oxytocin failed to expel the product of conception. Mean $( \pm S D$ ) time required for expulsion of product of conception was $11.44 \pm 4.43$ hours in $25(50 \%)$ women who were given tab cytomis only, in others, the time was much higher. The side-effects experienced by the patients were negligible, only one patient $(2 \%)$ had gastrointestinal cramps and diarrhoea, 2(4\%) patient's experienced febrile reaction and $3(6 \%)$ patients complained of nauseas and only $1(2 \%)$ patients vomited twice. The patients who had complete expulsion with Misoprostl (Tab Cytomis) did not require blood transfusion. Only $7(14 \%)$ cases that needed surgical evacuation experienced bleeding more that average and were treated with blood transfusion.
In a study conducted by Zalanyi (Hungary), Misoprostl 200 ug was used vaginally for expulsion of product of conception in missed abortion. The results showed that 5 (out of 25 ) had a complete abortion after 1st dose, 13 after second, 4 after third and the mean induction expulsion time was 6.1 hours (calculated only for successful cases). Three patients did not abort even after four doses, which required surgical evacuation of the uterus. There was no febrile complication. In a study carried out by Wood, 80 percent subjects aborted completely after two vaginal does of $800 \mathrm{ug}$ of Misoprostl table. It may be noted that does used was quite high in comparison to the present study. In that study, there was also an additional benefit of soft dilated cervix found during surgical treatment. There was no occurrence of lifethreatening bleeding and none of the patient needed blood transfusion.

In a study by Refacy et al, it was found that vaginal administration was more effective than the oral route. The local effect of Misoprostl on the cervix was considered to be one of the reasons. In a study carried out in Bangladesh by Barua ${ }^{15}$ using two tablets of Misoprostl vaginally, it was found that 60.71 percent patients had complete expulsion with vaginal Misoprostl, and among these, 42.85 percent patients responded with 1st does of $400 \mathrm{ug}$ of Misoprostl, mean ( $\pm S D$ ) induction-expulsion time being $8.30 \pm 2.53$ hours. Only 1 patient (out of 56) experienced shivering as a complication and 2 (out of 56) developed severe bleeding). This study shows that complete expulsion with Misoprostl tablet was more in patients with higher gestational age (21-29 weeks). Patients who were of 13-16 weeks gestational age needed more surgical evacuation. In this study, a number of patients needed surgical evacuation, but one of the important observations is that in this case, cervix was very soft and somewhat dilated during evacuation which reduced the risk of operation.

\section{Conclusion}

Gynaecologists have recently been challenged to rethink their approach to miscarriage. The doctrine of prompt surgical evacuation has been challenged by a small number of studies in women with incomplete abortions. 
Furthermore, the high success rates (more than $90 \%$ ) in the medical therapeutic abortion also suggest that nonsurgical treatment should be considered. The appropriate Misoprostl dose for mid trimester abortion has not been established and debate still exists concerning Misoprostl administration during pregnancy. So, there is urgent need to evaluate all available information for appropriate doses and safety required for registration. Given growing emphasis on improving female health, is undoubtedly becoming more important at present and in the future to that a case of second trimester abortion by a safe method. If Misoprostl proves safe and effective, a large number of patients will be benefited and will escape from surgical intervention and complications.

\section{References}

1. Chamberlain GVP. Fetal loss in early pregnancy. In: Obstetrics by ten teachers. 16th ed. Avon: Edward Arnold, 1995 : 156-62.

2. Demetroulis C. Saridogan E. Kunde D. Naftalin AA. A prospective randomized trial comparing medical and surgical treatment for early pregnancy failure. Hum Report 2001; 16 (2) : 365-9.

3. Dutta DC. Haemorrhage in early pregnancy. In: Textbook of obstetrics.6th ed. Calcutta: New Central Book Agency (P) Ltd, 2005:159-202.

4. Buckett W, Regan L. Sporadic and recurrent miscariage .Shaw,Soutter, Stanton Gynaecology. 3rd ed.Elsevier Science Limited, 2003:343-6.

5. G.C.M. Graziosi. B.W. Mol. W.M. Ankum. H.W. Bruense. Management of early pregnancy loss. Int J Gynaecol Obstet 2004; 86 (3): 337-46.

6. Hughes J, Ryan M, Hinshaw k, Henshaw R, Rispin R, Templeton A. The costs treating miscarriage; a comparison of medical and surgical management. $\mathrm{Br} \mathrm{J}$ Obstet Gynaecol 1996; 103: $1217-21$

7. Templeton A. Misoprostl for all? $\mathrm{Br} \mathrm{J}$ Obstet Gynaecol 1998 ; 105: 937-9.

8. Toppozada Mk, Anwar My, Hasan HA, el Gazaerly WS. Oral or vaginal Misoprostl for induction of labor. Int J Gynaecol Obstet 1997; 56:135-9.
9. EL Refaey H, Rajasekar D, Abdalla M, Calder L, Templeton A. Induction of abortion with mifepriston and oral or vaginal Misoprostl. N Engl J Med 1995; 332:983-7.

10. Daya S. Habitual abortion. In: Copeland LJ, editor. Textbook of gynecology. Philadelphia. WB Saunders Company, 2000: 227-71.

11. Crcinin M, Moyer R, Guido R. Misoprostl for medical evacuation of early pregnancy failure. Obstet Gynecol 1997; 89: 768-72.

12. Meller JL, Shermeta DW. Falls in urban children: a problem revisited. Am J DisChild .1987; 141:1271-5.

13. Velcek FT, Weiss A, DiMaio D, Koltz DH Jr., Kottmeir PK. Traumatic death in urban children. $\mathrm{J}$ Pediatr Surg 1977;12: 75-384.

14. Lehman D, Schonfeld N. Falls from heights: a problem not just in the northeast. Pediatrics .1993; 92: 1-124.

15. Barlow B, Niemirska M, Gandhi R, Leblanc W. Ten years of experience with falls from a height in children. J Pediatr Surg. 1983; 18:509-11.

16. Pathak A, Desania NL, Verma R.Prifle of Road Traffic Accidents and Head injury in Jaipur. J Indian Acad Forensic Med 2008; 30(1):6-10.

17. Reddy KSN. The Essentials of Forensic Medicine and Toxicology. 31st ed. India: Medical Book Coy; 2013 p.232-41.

18. Knight B, Saukko P. Knight's Forensic Pathology. 3rd ed.London.Arnold.2004 p174-222.

19. Roshkow JE, Haller JO, Hotson GC, Sclafani SJ, Mezzacappa PM, Rachlin S. Imaging evaluation of children after falls from a height: review of 45 cases. Radiology.1990; 175:359-63.

20. Mathis RD, Levine SH, Phifer S. An analysis of accidental free falls from a height: the "spring break" syndrome. J Trauma .1993; 34:123-6.

21. Williams RA. Injuries in infants and small children resulting from witnessed and corroborated free falls. J Trauma. 1991; 31:1350-2.

22. Reiber GD. Fatal falls in childhood: how far must children fall to sustain fatal head injury? Am J Forensic Med Pathol 1993; 14:201-7. 